\title{
Spruce Decline and Diaporthe: Incidence, Taxonomy, Virulence, and Tree Susceptibility in Michigan
}

C. K. McTavish, Tree Fruit Research Laboratory, USDA-ARS, Wenatchee, WA 98801; M. Catal, Department of Plant Protection, Faculty of Agriculture, Akdeniz University, TR-07058, Antalya, Turkey; D. W. Fulbright, Department of Plant, Soil, \& Microbial Sciences, Michigan State University, East Lansing, MI 48824; and A. M. Jarosz, ${ }^{\dagger}$ Department of Plant Biology and Program in Ecology, Evolutionary Biology and Behavior Program, Michigan State University, East Lansing, MI 48824

\begin{abstract}
In the early 2000s, spruce trees in Michigan began displaying basal needle drop and branch death that slowly progressed upward, symptoms of what we call spruce decline. A survey in 2013 revealed that spruce decline was common throughout Michigan's Lower Peninsula, and Diaporthe was the most likely pathogen causing the cankers associated with these symptoms. Greenhouse inoculation studies completed Koch's postulates, confirming that Diaporthe could cause cankers that cause needle loss and branch death. The five different Diaporthe haplotypes isolated from symptomatic branches during the survey differed in virulence. Haplotypes 2, 4, and 5 were more virulent, and differed from each other by only one or two base pairs using the internal transcribed spacer (ITS) region and did not differ using the $\beta$-tubulin (TUB) gene. These haplotypes were unresolved phylogenetically.

Haplotypes 1 and 3 were weakly virulent to avirulent on multiple spruce taxa, and fell into a resolved Diaporthe eres clade. Spruce taxa varied in susceptibility, with Colorado blue spruce (Picea pungens) the most susceptible, followed by Norway ( $P$. abies), then white spruce $(P$. glauca). Spruce taxa that were much less susceptible were Black Hills ( $P$. glauca var. densata), Serbian ( $P$. omorika), and Meyer spruce (P. meyeri). We demonstrate that one or more Diaporthe species is causing cankers on declining spruce in Michigan, and these cankers elicit symptoms similar to the branch death expressed by declining spruce in the landscape. Future work will focus on further characterizing Diaporthe to species, and determining biotic and abiotic stressors that may predispose spruce trees to express decline symptoms.
\end{abstract}

Narrow-leaved evergreens are an important commodity in Michigan, encompassing $65 \%$ of Michigan's woody plant acres in production (Michigan Department of Agriculture and USDA NASS 2005). Michigan ranks third in the country for acres of Christmas trees, with 1,739,538 Christmas trees cut in 2012 alone (USDA NASS 2012). A recent estimate found that $23 \%$ of Christmas tree acreage in Michigan was spruce, with Colorado blue spruce (Picea pungens Engelm.) accounting for almost half of spruce Christmas tree production (USDA NASS 2014). Spruce trees are also important landscape trees, ranking second in abundance and comprising $12 \%$ of all urban and community trees in Midwestern cities (Wade 2010).

Unfortunately, in the early 2000s, spruce trees began displaying symptoms of what we term spruce decline (Jill O'Donnell and D. W. Fulbright, personal communication). Initial symptoms include the loss of needles more than 1 year old on the lowest branches of primarily mature trees. Over time, current year needles begin to die followed by the death of lateral branches closest to the trunk. Needle loss and lateral branch death continues outward from the trunk until the whole branch succumbs to disease. Whole branch death usually begins at the bottom of the tree and progresses slowly upward over multiple years, ruining the aesthetic appeal (Fig. 1).

This symptomology is associated with many tree declines, which are multifaceted diseases that primarily affect mature trees. Characterized by slow deterioration in health and vigor, tree declines have a complex etiology influenced by multiple abiotic and biotic factors (Manion 1991). Spruce decline has caused havoc in the nursery and landscape industry, with sales decreasing and costs increasing. According to a recent grower poll, spruce decline is causing losses of $\$ 16,250$ per grower (Jill O'Donnell, Survey at the Michigan

${ }^{\dagger}$ Corresponding author: Andrew M. Jarosz; E-mail: amjarosz@msu.edu

Funding: Estate of Miriam C. Strong; MSU AgBioResearch; MDARD (136863); MSU GREEEN (GR14-018).

Accepted for publication 5 May 2018.

() 2018 The American Phytopathological Society
Christmas Tree Association 2014 winter meeting; unpublished), which is a significant impact on growers because $70 \%$ of Michigan operations have less than 25 acres (USDA NASS 2014).

While partial needle loss could be due to diseases like Rhizosphaera kalkhoffii, or the unconfirmed pathogens Stigmina lautii and Setomelanomma holmii (SNEED), the ability to cause both needle loss and progressive mortality of entire branches suggested that a canker-causing pathogen was contributing to decline symptoms (Hodges 2002; Rossman et al. 2002; Sinclair and Lyon 2005; Walla and Kinzer 2006). Preliminary work found that cankers were indeed associated with branch death and needle loss. However, Cytospora kunzei Sacc, a well-characterized canker-causing pathogen of spruce, was only rarely isolated from these cankers (Hansen and Lewis 1997; Sinclair and Lyon 2005). Unlike Cytospora cankers, which commonly display resinous streaks on the branch above the canker, cankers causing spruce decline were not evident until the bark was scraped back to expose the phloem and vascular cambium layers (D. W. Fulbright and S. Stadt, unpublished data). Cankers were brown with occasional resinous streaking found within the phloem and cambium layers, and did not spread into the xylem (Fig. 1). Multiple cankers were found on most dying branches.

This study was undertaken to discover the canker causing pathogen associated with spruce decline in Michigan. Four fundamental questions were addressed concerning spruce decline: i) Where is spruce decline located in the Lower Peninsula of Michigan? ii) Which fungi are associated with cankers, and what genus is the most likely pathogen causing cankers on declining trees? iii) How variable is the pathogen? iv) How susceptible are commonly planted spruce taxa to the decline pathogen?

\section{Materials and Methods}

Spruce decline survey in the Lower Peninsula of Michigan. In the summer of 2013, spruce trees were surveyed to estimate the spatial distribution of spruce decline and to obtain canker samples for laboratory isolation. The Lower Peninsula was divided into four regions and within each region, six sites (five in the central region) were chosen so all areas of the Lower Peninsula were represented (Fig. 2). At each site, eight mature trees from predominantly landscape settings were selected that were separated by at least $160 \mathrm{~m}$ and exhibited spruce decline symptoms, with the exception of East 
3 , where seven trees were selected. A single dying branch that displayed spruce decline symptoms but had not yet senesced completely was collected from each tree. Partially dying branches were chosen to maximize the likelihood of isolating true pathogens, because completely senesced branches would have had weakened defense systems, allowing opportunistic microorganisms to invade. Conversely, a symptomless branch would have had a lower likelihood of locating the smaller, developing cankers on those branches as disease developed. To expose cankers on dying branches, the top layer of bark no deeper than the vascular cambium was scraped away (Fig. 1B). The first two cankers uncovered on each branch were sampled. In total, isolates were obtained from 393 cankers on the 159 branches collected across the Lower Peninsula of Michigan.

Fungal isolation and sequencing. Canker tissue samples were cut into approximately $3 \mathrm{~mm} \times 3 \mathrm{~mm}$ segments and surface-sterilized in a $10 \%$ bleach solution for $1 \mathrm{~min}$, followed by two 1-min rinses in sterile deionized water. Three segments per canker were plated on Petri plates containing full strength potato dextrose agar (PDA, Difco, Franklin Lakes, NJ). Four to six days later, a representative of each fungal morphology on the plate was subcultured to fresh PDA plates by hyphal tipping. Data from three sites in the west region were not included in summary statistics because slightly different protocols were followed. Once subcultured, isolates were grouped initially by morphotype, and taxonomic identification of the five most common morphological groups was confirmed by sequencing the internal transcribed spacer (ITS) region of the nuclear ribosomal RNA gene operon using ITS1 and ITS4 primers (White et al. 1990). In addition to the five most common morphotypes, three known conifer pathogen genera, Cytospora, Fusarium, and Pestalotiopsis, were also confirmed by sequencing the ITS region. Diaporthe isolates were stored on filter paper and agar plugs in double distilled autoclaved water for future species identification.

ITS sequencing was executed using protocols revised from Catal et al. (2010). Single spore isolates were grown in potato dextrose broth (PDB, Difco Laboratories) for 14 days, at which time the liquid was vacuumed away using a Büchner funnel with grade 1 Whatman cellulose filter paper (GE Healthcare). Between 50 and $100 \mathrm{mg}$ of hyphae were lyophilized and ground in $1 \mathrm{ml}$ of $2 \%$ hexadecyltrimethylammonium bromide buffer until viscous and incubated at $65^{\circ} \mathrm{C}$ for $60 \mathrm{~min}$. Following centrifugation at 13,000 rpm for $5 \mathrm{~min}, 0.7 \mathrm{ml}$ of supernatant was pipetted to QIA shredder mini-column (Qiagen Inc.) and centrifuged at 13,000 rpm for $2 \mathrm{~min}$. Approximately $0.5 \mathrm{ml}$ of supernatant was precipitated with $0.3 \mathrm{ml}$ cold $95 \%$ ethanol, and was transferred to DNeasy mini-columns. DNA was washed and eluted following Qiagen DNeasy Plant Mini Kit protocol. Amplification reactions had a total volume of $25 \mu 1$, consisting of $12.5 \mu \mathrm{l}$ of GoTaq (Promega) Green Master Mix, $2.5 \mu l$ of each ITS 1 and ITS4, $2 \mu \mathrm{l}$ DNA, and $5.5 \mu \mathrm{l}$ of nuclease-free water. PCR conditions consisted of initial denaturation at $95^{\circ} \mathrm{C}$ for $2 \mathrm{~min}$, followed by 30 cycles of $55^{\circ} \mathrm{C}$ for $30 \mathrm{~s}, 72^{\circ} \mathrm{C}$ for $60 \mathrm{~s}$, and $95^{\circ} \mathrm{C}$ for $30 \mathrm{~s}$, with a final extension at $72^{\circ} \mathrm{C}$ for $10 \mathrm{~min}$. Samples were purified using ExoSAPIT (Affymetrix, Santa Clara, CA), and were sequenced in the Genomics Core of the Research Technology Support Facility at Michigan State University using the Applied Biosystems BigDye v3.1 chemistry following manufacturer's instructions and then analyzed on an Applied Biosystems 3730xl sequencer.
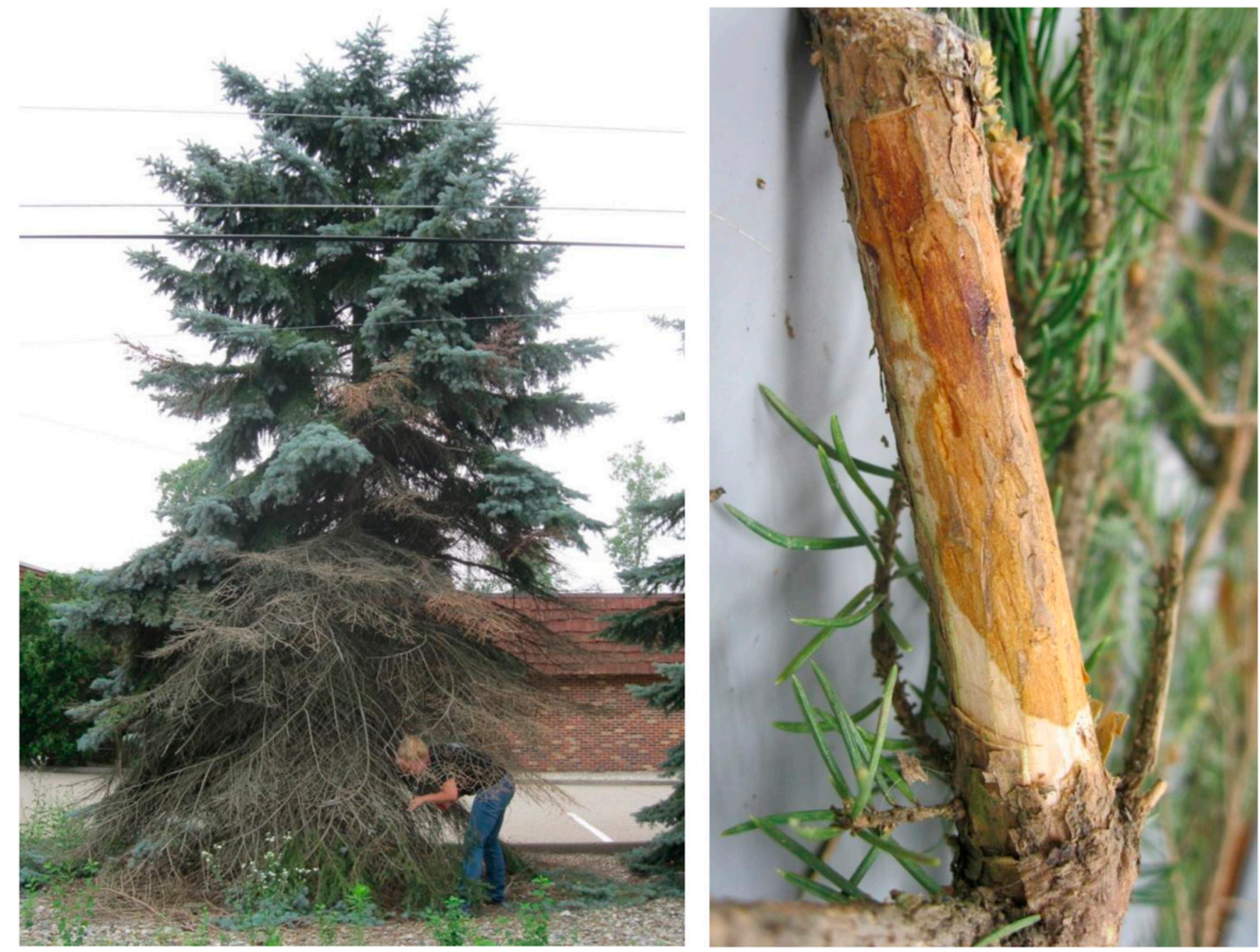

Fig. 1. Left, Colorado blue spruce displaying spruce decline symptoms of needle drop and branch death beginning at the bottom of the tree and progressing upward. Right, a segment of the top layer of bark on the branch was removed to reveal a brown canker, with uninfected plant tissue appearing white. 
Phylogenetic analyses. The genus Diaporthe encompasses many different species that act as plant pathogens, endophytes, and saprobes, often with wide host ranges (Gomes et al. 2013; Santos and Phillips 2009; Udayanga et al. 2011). Species from this genus have traditionally been named according to host from which they were isolated (Uecker 1988); however, this has caused many problems, since many Diaporthe species are not host-specific (Crous and Groenewald 2005; Rehner and Uecker 1994; Uddin et al. 1997), making positive confirmation of specific epithet complicated. For this reason, it was decided to focus on genus-level variability in order to identify the potential intensity of disease and population dynamics and determine species-level information at a later date. To assess the genus level variability among the Diaporthe isolates, 23 samples sequenced using ITS as described above were also sequenced for the $\beta$-tubulin (TUB) gene using primers Bt2a and Bt2b (Glass and Donaldson 1995). PCR conditions were the same as described for ITS amplification. Sequences were edited using BioEdit (Hall 1999), aligned separately by gene using ClustalW, visually checked, and minimally adjusted. A partition homogeneity test using the branch and bound method was performed in PAUPv4.0a159 (Swofford 2002), and resulted in a $P$ value of 0.001 , so the genes were analyzed separately. Sequences were visualized as minimum spanning trees in PopART (Bandelt et al. 1999; http://popart.otago.ac.nz).

After comparing these haplotypes to each other, we then compared them to other known species. To do this, a representative of each Diaporthe haplotype above was chosen for analysis using both ITS and TUB sequences. To choose comparative sequences, a BLAST search was performed using the ITS sequence from each haplotype. Species that were closely related were then compared with the phylogenetic tree from Gomes et al. (2013), and 15 species were chosen, downloading the ITS and TUB genes from the NCBI database using the accession numbers provided by Gomes et al. (Table 1). Neighborjoining (Saitou and Nei 1987), maximum-likelihood, and maximum parsimony phylogenetic analyses were performed using MEGA6 (Tamura et al. 2013) and Bayesian phylogenetic analyses were

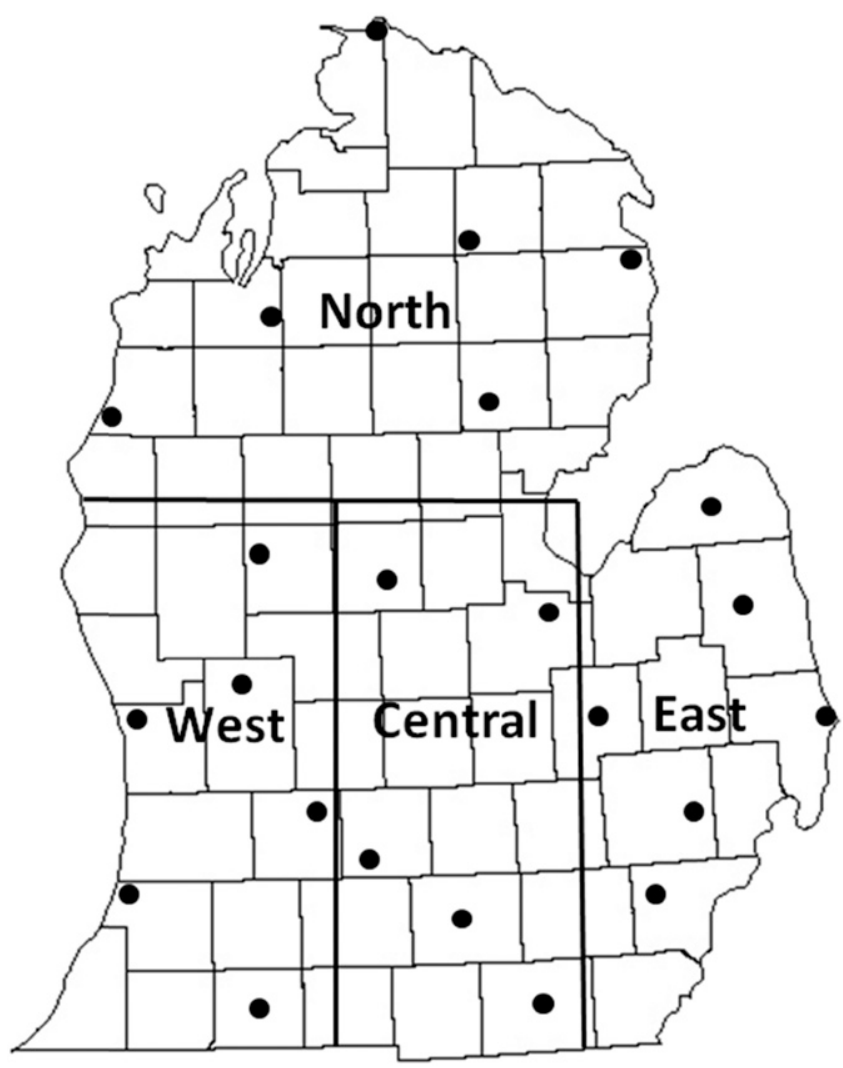

Fig. 2. Regions and sites of the 2013 spruce decline canker survey. Dots represent sites. performed using MrBayes v3.2.6 (Ronquist and Huelsenbeck 2003). All trees were rooted with Diaporthella corylina. The Kimura 2-parameter nucleotide substitution model was used for evolutionary distance analysis with an estimated gamma distribution for all ITS analyses (Kimura 1980), and the Tamura 3-parameter model with invariant sites was used for TUB analyses (Tamura 1992). Bootstrap analysis (Felsenstein 1985) was performed for statistical support of branches in neighbor-joining (2,000 replicates), maximumlikelihood, and maximum parsimony analyses, bootstrap analysis (all 1,000 replicates), while Bayesian analyses used posterior probabilities.

Maximum likelihood analysis used nearest-neighbor-interchange (NNI) as the optimal tree search. To search the tree space in the parsimony analysis, tree-bisection-reconnection (TBR) was employed using all characters (Nei and Kumar 2000), and the consensus tree was formed using the most parsimonious trees. Bayesian phylogenetic trees were generated under default priors and likelihood settings, as not much was known prior to the start of analysis. The Markov Chain Monte Carlo (MCMC) analysis of four chains was run for 250,000 generations, sampling every 100 generations using a burn-in of 5,000 generations (20\%), with the average standard deviation of split frequencies resulting in less than 0.01 . The phylogenetic tree was formatted in FigTree v1.4.2 (Rambaut 2012).

Pathogen virulence and spruce susceptibility inoculations. Two inoculation experiments were carried out in different Michigan State University greenhouses from 2013 to 2014. For both experiments, temperature and sunlight varied with natural day/night cycle, and internal temperatures were controlled by venting. In the 2013 experiment, swamp coolers were used to control conditions, while the greenhouse for 2014 was not properly equipped to use them. Greenhouses were whitewashed in early summer to reduce light intensity and reduce day-time temperatures. At the conclusion of each experiment, cankers were resampled for Diaporthe and Koch's postulates were confirmed by sequencing the ITS region following abovementioned protocols to confirm that the canker was caused by the haplotype originally inoculated onto the tree.

Experiment 1: Evaluating virulence across Diaporthe isolates. Six Diaporthe isolates collected in Michigan were inoculated onto three common spruce taxa grown in the state: Colorado blue (Picea pungens Engelm.), Norway (P. abies (L.) H. Karst.), and white spruce (P. glauca (Moench) Voss). Collectively, the six isolates encompassed the range of variability for ITS sequence, colony color, geographic region, and host of origin (Table 2). The 3-year-old trees ( 2 years in a seed bed, 1 year in a transplant bed, or 2-1) were purchased from a nursery on the west side of the Lower Peninsula of Michigan. One hundred trees from each spruce taxon were planted from 5 to 8 May 2013 into $10.2 \times 10.2 \times 35.6 \mathrm{~cm}$ pots filled with Suremix perlite soil (Michigan Grower Products Inc., Galesburg, MI). Tree roots were cut to mimic transplant damage as well as to fit in pots properly. During 28 to 30 May 2013, approximately 20 days after planting during which budbreak had occurred, 15 trees from each spruce taxon were inoculated per Diaporthe haplotype, and an additional 10 trees served as negative controls that were inoculated with a sterile plug of PDA. Prior to inoculations, all Diaporthe isolates were grown on PDA under ambient lighting for approximately 10 days to allow full expansion of the mycelia across the $90 \mathrm{~mm}$ diameter Petri plate. Inoculations were carried out by making a small $2 \times 2 \times 3 \mathrm{~mm}$ hole in the stem approximately $4 \mathrm{~cm}$ above the soil line, and placing a $2 \times 2 \mathrm{~mm}$ mycelial disc in the hole. The inoculation site was sealed by wrapping Parafilm around the stem and was not removed. Wounding was necessary for mycelial infection (Igoe et al. 1995).

Trees were watered every other day to saturation. Approximately 56 days postinoculation, canker area was determined by destructively sampling the inoculated stems. Length and width of the canker formed at the inoculation site were measured after scraping off the top layer of bark.

Experiment 2: Evaluating spruce taxa for susceptibility to Diaporthe. Six commonly planted spruce taxa were inoculated with Diaporthe to determine differences in susceptibility: Colorado blue 
(P. pungens), Norway ( $P$. abies), white $(P$. glauca), Black Hills (P. glauca var. densata Bailey), Serbian (P. omorika [Pancic] Purk.), and Meyer ( $P$. meyeri [Rehder] E.H.Wilson) spruce. The trees were purchased from a nursery on the west side of the Lower Peninsula of Michigan. Most trees were 3 years old (2-1), with the exception of $P$. glauca var. densata and $P$. meyeri, which were 4 years old (2-2) to ensure proper diameter for inoculations. Stem diameter of the trees averaged $0.85 \mathrm{~cm}$ and ranged from 0.40 to $1.96 \mathrm{~cm}$. Three Diaporthe isolates were used for inoculations: two from virulent haplotypes (4 and 5) and a third from the largely avirulent haplotype (3b) based on the results of the previous experiment.

Trees were planted between 10 and 21 April 2014. For each spruce taxon, 330 trees were planted as described in the first experiment. Approximately 19 days after planting (7 to 14 May), during which time the trees had broken bud, trees were inoculated as described above with one of the three Diaporthe isolates. Fungal isolates were grown on PDA plates for approximately 10 days to allow mycelia to cover the plate. A sterile PDA plug served as a negative control. Sixty trees from each spruce taxon were inoculated per treatment (i.e., three separate Diaporthe isolates and the negative control), and 60 trees were not inoculated to serve as environmental controls to confirm symptoms were not caused by environmental conditions in the greenhouse.

Trees were watered every other day to saturation, and were treated for aphids on 23 June 2014. Approximately 78 days postinoculation (23 to 31 July), stems were sampled destructively, as described above, to measure the canker area at the inoculation site.

Statistical analyses. Data analyses were performed in SAS (SAS Institute 2013). Generalized linear model (GLM) analysis of variance was carried out on each inoculation experiment using the PROC GLIMMIX function. Fixed effects included species, inoculum haplotype, and species by inoculum interaction. Post-hoc analyses were performed on least-squares means using the Tukey-Kramer method. To reduce heteroscedasticity, canker area data were $\log _{10}$ transformed after adding one to each datum. Results have been backtransformed for presentation.

\section{Results}

Spruce decline survey. Spruce decline was found throughout the Lower Peninsula of Michigan, and declining trees were never difficult to locate at any location. The majority of sampled trees were blue spruce trees $(77 \%)$, as this species is a popular landscape tree in Michigan and our results indicated it was highly susceptible to spruce decline. Other trees sampled included Norway and white spruce. Cankers were not visible on collected branches until the bark was scraped back, where brown cankers were observed in the bark, phloem, and vascular cambium, but not penetrating further into the branch (Fig. 1B). Cankers were found on all but one of the 159 branches collected in the survey.

Isolations were attempted from 393 cankers: 109 cankers in the central region (seven of which did not yield fungi): 48 cankers in the west (five of which did not yield fungi), 134 cankers in the east, and 102 cankers in the north (10 of which did not yield any fungi). The overall average for all regions was 1.8 isolates per canker with slightly different numbers across the four regions. An average of 2.1 isolates per canker were obtained from the central region, 1.4 isolates in the west, 2.2 isolates in the east, and 1.6 isolates in the north. The five most common fungal genera isolated from cankered tissue

Table 1. Strain, isolation source, country of origin, and GenBank accession numbers used in the study

\begin{tabular}{|c|c|c|c|c|c|}
\hline \multirow[b]{2}{*}{ Species } & \multirow[b]{2}{*}{ Strain } & \multirow[b]{2}{*}{ Isolation source } & \multirow[b]{2}{*}{ Country of origin } & \multicolumn{2}{|c|}{ GenBank accession number } \\
\hline & & & & ITS & TUB \\
\hline Diaporthe alleghaniensis & CBS 495.72 & Betula alleghaniensis & Canada & KC343007 & KC343975 \\
\hline Phomopsis amygdali & CBS 126679 & Prunus dulcis & Portugal & KC343022 & KC343990 \\
\hline Diaporthe celastrina & CBS 139.27 & Celastrus scandens & - & KC343047 & KC 344015 \\
\hline Diaporthe eres & CBS 102.81 & Juglans regia & Italy & KC343074 & KC344042 \\
\hline Diaporthe eres & CBS 186.37 & Picea abies & UK & KC343079 & KC344047 \\
\hline Diaporthe eres & CBS 287.74 & Sorbus aucuparia & Netherlands & KC343084 & KC344052 \\
\hline Diaporthe eres & CBS 375.61 & Malus sylvestris & - & KC343088 & KC344056 \\
\hline Diaporthe eres & CBS 439.82 & Cotoneaster sp. & UK: Scotland & KC343090 & KC344058 \\
\hline Diaporthe helianthi & CBS 592.81 & Helianthus annuиs & Serbia & KC343115 & KC344083 \\
\hline Diaporthe vaccinii & CBS 122112 & Vaccinium macrocarpon & USA: New Jersey & KC343224 & KC344192 \\
\hline Diaporthe vaccinii & CBS 122114 & Vaccinium corymbosum & USA: Michigan & KC343225 & KC344193 \\
\hline Diaporthella corylina & CBS 121124 & Corylus sp. & China & KC343004 & KC343972 \\
\hline Diaporthe bicincta & CBS 121004 & Juglans sp. & USA: Tennessee & KC343134 & KC344102 \\
\hline Diaporthe nobilis & CBS 587.79 & Pinus pentaphlla & Japan & KC343153 & KC344121 \\
\hline Diaporthe decedens & CBS 109772 & Corylus avellana & Austria & KC343059 & KC344027 \\
\hline Diaporthe haplotype 1 & - & Thuja occidentalis & USA: Michigan & MG452402 & MG735768 \\
\hline Diaporthe haplotype 2 & - & Picea pungens & USA: Michigan & MG452403 & MG735771 \\
\hline Diaporthe haplotype 3 & - & Picea pungens & USA: Michigan & MG452404 & MG735769 \\
\hline Diaporthe haplotype 4 & - & Picea pungens & USA: Michigan & MG452405 & MG735772 \\
\hline Diaporthe haplotype 5 & - & Picea pungens & USA: Michigan & MG452406 & MG735770 \\
\hline
\end{tabular}

Table 2. Diaporthe isolates used to assess virulence patterns. Collectively, the isolates encompass the known variability for ITS haplotype, colony color, geographic region, habitat, and host of origin

\begin{tabular}{llllll}
\hline Isolate code & Diaporthe $^{\text {haplotype }} \mathbf{y}^{\mathbf{y}}$ & Colony color & Region within Michigan & Habitat & Host \\
\hline 90 & 1 & White & West & Forest & Nursery pungens \\
5 & 2 & Gray & Central & Llauca \\
15 & $3 \mathrm{a}$ & White & Central & Landscape & Thuja occidentalis \\
68 & $3 \mathrm{~b}$ & Gray & West & Nursery & P. pungens \\
53 & 4 & White & North & Landscape & P. pungens \\
82 & 5 & Gray & Central & Nursery & P. pungens \\
\hline
\end{tabular}

y Haplotypes were determined using sequences from the internal transcribed spacer region (ITS). The five haplotypes differed based on substitutions and insertions at 11 variable positions along the 600 base pair sequences. Isolates 15 and 68 have identical ITS sequences corresponding to haplotype 3.

${ }^{\mathrm{z}}$ Cultures were grown on full strength PDA agar for 10 days in ambient lighting. 
accounted for $58 \%$ (439 out of 759) of the total isolates. No other morphological group had an occurrence greater than $3 \%$ of the total isolates, and thus was not identified, as they were not common enough to be causing widespread spruce decline. Three exceptions were made for Cytospora, Fusarium, and Pestalotiopsis, genera that contain known conifer pathogens.

The two most common genera isolated were Paraconiothyrium and Diaporthe. While their prevalence differed slightly among regions, these two taxa were either the first or second most common genus isolated within each region (Fig. 3). Paraconiothyrium was more common than Diaporthe in both the north and east regions of Michigan, while Diaporthe was the most common in the west and

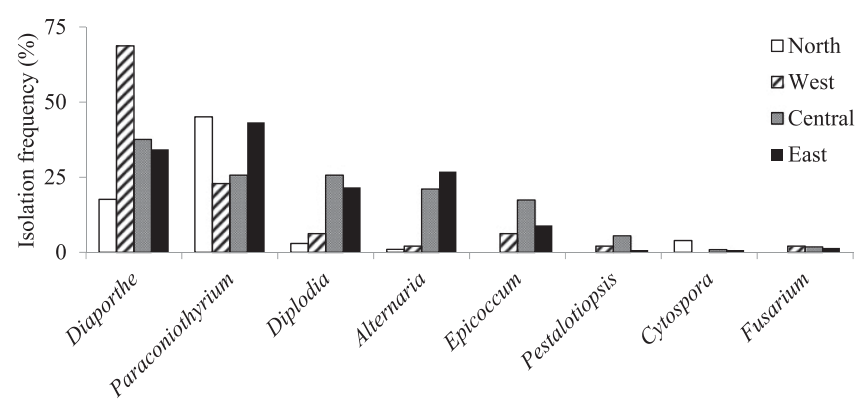

Fig. 3. Frequency of isolation of fungal genera from cankers collected as part of the survey. Regional total percentages are based upon cankers that contained the taxon. central regions. The widespread occurrence of both fungal genera presents the possibility that either could be involved in causing spruce decline.

Diplodia and Alternaria were the only other genera isolated from spruce cankers in all areas of Michigan (Fig. 3). However, both genera were rarely sampled in both the north and west regions of the state, being found on less than $7 \%$ of sampled cankers in both regions (Fig. 3). The fifth most common genus, Epicoccum, was not detected in the north region of the Lower Peninsula. The three known canker pathogens of conifers, Cytospora, Pestalotiopsis, and Fusarium, never exceeded $6 \%$ of the isolates recovered in any one region and their cumulative frequencies across the whole of the Lower Peninsula were 1, 2, and 1\%, respectively. Pestalotiopsis and Fusarium were not detected in the north region, while Cytospora was not found in the west region of the state. The rarity of these three potential pathogen taxa across Michigan argues against them being major components of the current spruce decline epidemic.

Phylogenetic results. A total of 452 base pairs (bp) from the ITS and $351 \mathrm{bp}$ TUB sequences from 23 Diaporthe isolates collected from declining spruce in Michigan were aligned for comparison. Analyses confirmed the presence of the same five haplotype sequences detected during preliminary studies. Haplotypes 2, 4, and 5 were closely related, differing by only one or two bp using ITS and identical using TUB. Using ITS, haplotype 1 differed from haplotype 5 by three bp changes, while haplotype 3 was the most distinct, differing from haplotype 1 by five additional bp changes. Using TUB, haplotypes 1 and 3 were also identical to each other, and differed from the grouping of haplotypes 2,4 , and 5 by five bp using

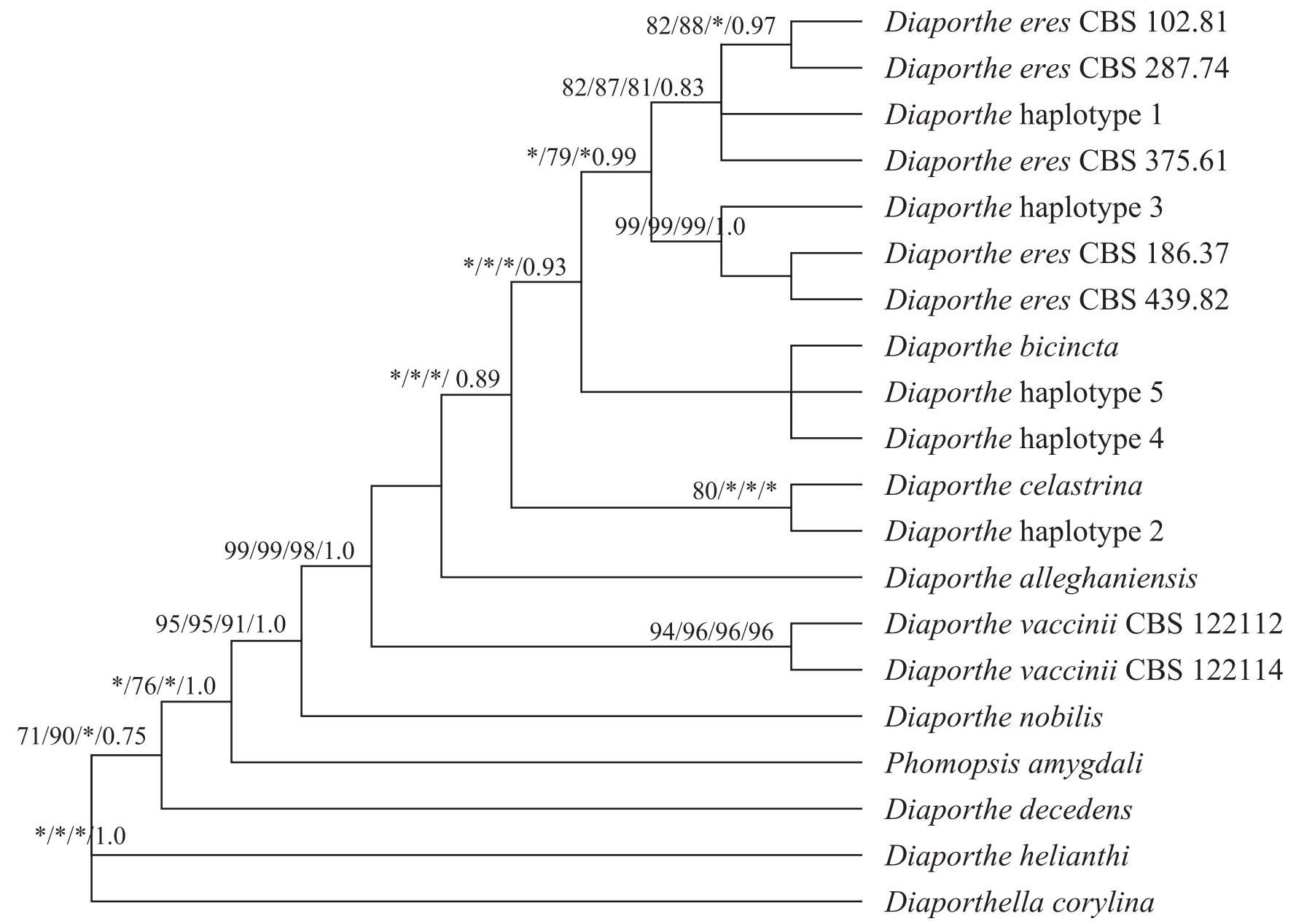

Fig. 4. Cladogram of the consensus tree (tree length 211) from parsimony analysis of TUB sequence data. The Kimura 2-parameter nucleotide substitution model was used for evolutionary distance analysis with an estimated gamma distribution. Bootstrap values are shown at the nodes, starting clockwise from the top: neighbor-joining, first mostparsimonious tree, maximum-likelihood, and Bayesian (posterior probabilities) analyses with a cutoff value of $70 \%$ or 0.7 . A * indicates a below-threshold support value. The cladogram was rooted with Diaporthella corylina. Analyses were performed in MEGA6 and MrBayes. 
TUB. There was no obvious geographical localization or host specialization for any haplotype, although the small sample size for sequenced isolates precluded drawing any definitive conclusions.

The phylogenetic datasets consisted of 19 ingroup and one outgroup (Diaporthella corylina) taxa. The ITS and TUB alignments contained 487 and 379 characters, respectively, including alignment gaps. Phylogenetic trees generated by neighbor-joining, maximumlikelihood, maximum-parsimony, and Bayesian analyses were topographically identical within gene, while there were slight differences between genes (Figs. 4, 5, and 6). For ITS maximum-parsimony, 362 characters were constant, 78 characters were parsimony-uninformative, and 47 were parsimony-informative. Six most parsimonious trees of tree length 173 were found, and for all sites and parsimony-informative sites in parentheses, the consistency index was $0.850(0.701)$, the retention index was 0.814 (0.814), and the composite index was 0.692 (0.571). For TUB maximum-parsimony, 241 characters were constant, 81 characters were parsimony-uninformative, and 57 characters were parsimonyinformative. Ten most parsimonious trees of tree length 211 were found, and the consistency index was $0.863(0.726)$, the retention index was $0.743(0.743)$, and the composite index was $0.641(0.540)$ for all sites and parsimony-informative sites in parentheses.

The five haplotypes detected in Michigan did not group into a single, well-supported clade in either gene analyzed (Figs. 4, 5, and 6). However, Diaporthe haplotypes 1 and 3 fell into well-supported Diaporthe eres clade(s) for both genes. The ITS sequence for Diaporthe haplotype 3 was identical to Phomopsis occulta, the same species identified in spruce canker diseases (Igoe et al. 1995; Sanderson and Worf 1986), but no TUB data were available for $P$. occulta. Additionally, P. occulta, formerly Phoma occulta, has been proposed to be renamed $D$. eres in an effort to reduce competing names within the genus (Rossman et al. 2014).

Despite their high sequence similarity, haplotypes 2, 4, and 5 did not form a single clade, but instead grouped into poorly resolved portion of the cladogram that included representatives from $D$. bicincta and D. celastrina.

Inoculation 1: Evaluating virulence across Diaporthe haplotypes. There were significant differences among the five Diaporthe haplotypes for virulence and among three spruce taxa for their level of resistance $(P=0.0001$ and $P=0.0098$, respectively, Table 3$)$. There also was a weak Diaporthe haplotype by spruce taxa interaction $(P=0.06)$. This interaction was caused by the two patterns of virulence across the three spruce taxa. Virulence for haplotypes 3 and 5 , which exhibited low and high levels of virulence, respectively, did not differ across the three spruce taxa (Fig. 7). Haplotypes 1, 2 , and 4 exhibited a second pattern where virulence on Colorado blue spruce was greater than on Norway and white spruce (Fig. 7). Negative controls did not yield cankers. Overall, Colorado blue spruce was the most susceptible of the three spruce taxa tested. Cankers were significantly larger in Colorado blue spruce $\left(0.92 \mathrm{~cm}^{2}\right.$ mean, 0.77 lower confidence interval, and 1.10 upper confidence interval) than either Norway $\left(0.38 \mathrm{~cm}^{2}, 0.29,0.48\right)$ or white $\left(0.54 \mathrm{~cm}^{2}\right.$, $0.45,0.63)$. Average canker sizes across haplotypes fell into three statistical groupings, with some overlap between the two groups exhibiting higher virulence (Table 4).

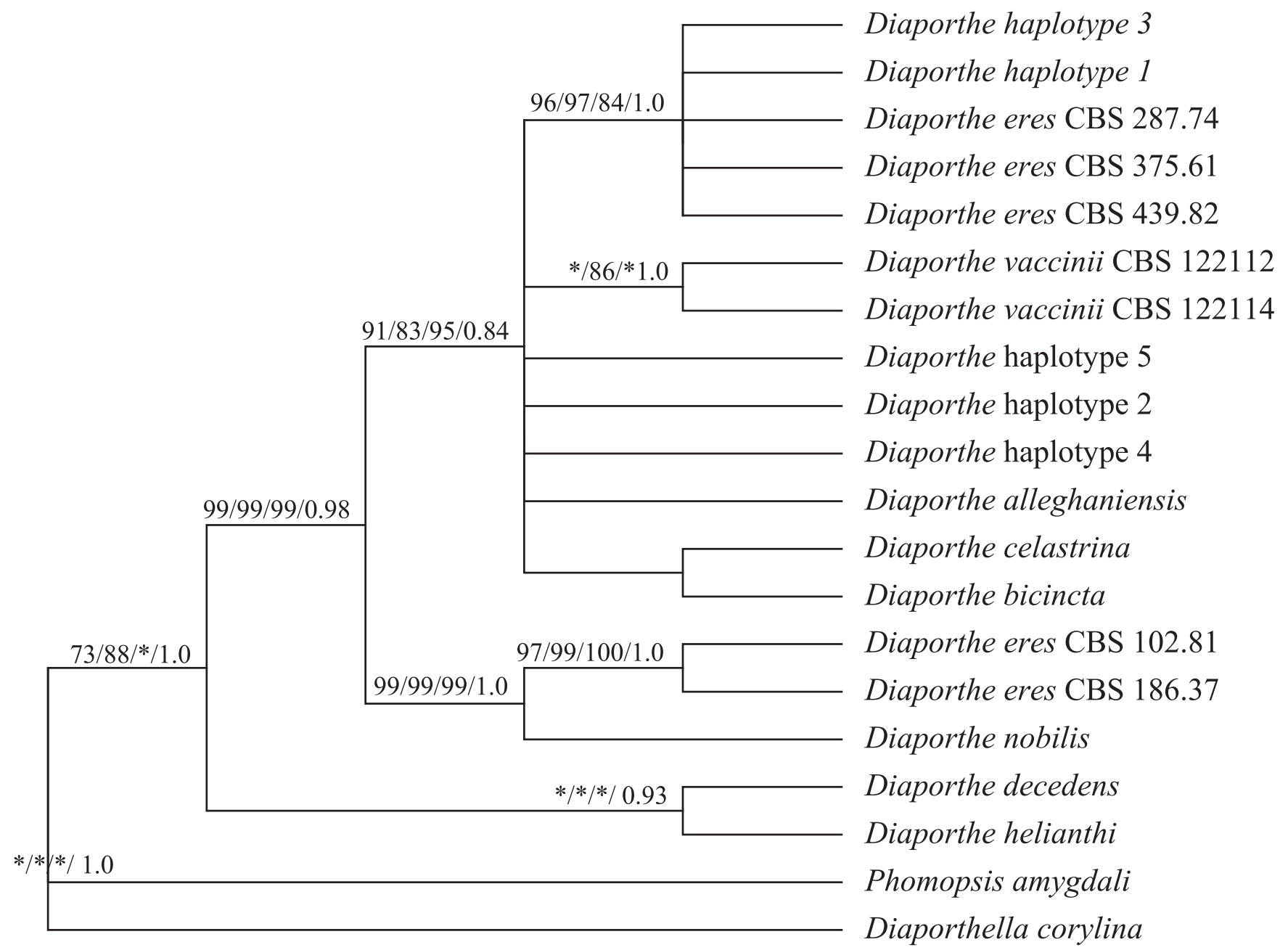

Fig. 5. Cladogram of the consensus tree (tree length 173) from parsimony analysis of TUB sequence data. The Tamura 3-parameter nucleotide substitution model was used for evolutionary distance analysis with invariant sites. Bootstrap values are shown at the nodes, starting clockwise from the top: neighbor-joining, first most-parsimonious tree, maximum-likelihood, and Bayesian (posterior probabilities) analyses, with a cutoff value of $70 \%$ or 0.7 . A * indicates a below-threshold support value. The cladogram was rooted with Diaporthella corylina. Analyses were performed in MEGA6 and MrBayes. 
Inoculation 2: Evaluating spruce taxa for susceptibility to Diaporthe. Six spruce taxa were inoculated with isolates from three Diaporthe haplotypes; haplotype 4 was highly virulent, haplotype 5 was moderately virulent, and haplotype 3 was avirulent on Colorado blue spruce. Spruce taxa were chosen because they are planted in Michigan as landscape trees. Analysis of variance indicated large differences among spruce taxa for their level of susceptibility to Diaporthe and significant difference among Diaporthe haplotypes to cause disease (Table 5). Additionally, the ANOVA indicated a highly significant interaction effect between spruce taxon and Diaporthe haplotype $(P<0.0001)$. Two spruce taxon by haplotype interaction patterns were evident. Haplotype 3 displayed the first pattern, and was uniformly avirulent across all six spruce taxa (Fig. 8 ). The more virulent haplotypes 4 and 5 displayed the second pattern where Colorado blue spruce was the most susceptible spruce taxon, followed by Norway, then white spruce. There was a slight tendency among these susceptible spruce taxa for cankers to be larger when trees were inoculated with the haplotype 4 isolate, but the difference was not statistically significant. Black Hills, Serbian, and Meyer spruce were largely resistant to Diaporthe haplotypes 4 and 5, but Meyer spruce was significantly more resistant to haplotype 4 than either Black Hills or Serbian spruce.

While sampling cankers for trees inoculated with Diaporthe haplotype 5, there was one $P$. glauca, nine $P$. abies, and three $P$. pungens trees with dark spore structures on the outer bark overlaying the canker on the main stem (Fig. 9). These spore structures also occurred on six $P$. abies and one $P$. pungens trees inoculated with Diaporthe haplotype 4 . These structures were harvested and observed under a compound microscope, where alpha and beta spores typical of Diaporthe were observed (Fig. 10).

A

Diaporthe eres CBS 102.81

Diaporthe eres CBS 287.74

Diaporthe eres CBS 375.61

Diaporthe haplotype 1

Diaporthe eres CBS 186.37

99

Diaporthe haplotype 3

Diaporthe eres CBS 439.82

- Diaporthe bicincta

Diaporthe haplotype 4

Diaporthe haplotype 5

Diaporthe haplotype 2

Diaporthe celastrina

98

Diaporthe alleghaniensis

$91 \quad 96$

Diaporthe vaccinii CBS 122112

Diaporthe vaccinii CBS 122114

- Diaporthe nobilis

Phomopsis amygdali

Diaporthe helianthi

Diaporthe decedens

Diaporthella corylina

0.05

(Continued)

Fig. 6. Phylograms of the maximum-parsimony analysis of A, ITS and B, TUB data using the best-fit models (Kimura 2-parameter and Tamura 3-parameter, respectively) using the nearest-neighbor-interchange heuristic search method using all sites. Trees with the highest log likelihoods are shown $(-1,497.7039,-1,441.3485)$, with bootstrap values $(1,000$ replications) displayed at nodes with a $70 \%$ cutoff value. Trees are rooted with Diaporthella corylina. 


\section{Discussion}

Spruce decline was found throughout the Lower Peninsula of Michigan with no obvious epicenter. While the disease was first noted on landscape trees starting in the early 2000s, it is surprisingly widespread. We also suspect spruce decline is not limited to Michigan, as descriptions from growers, extension agents, and tree companies in other states match spruce decline symptoms (Jill O'Donnell, D. W. Fulbright, and C. K. McTavish, personal communication). Cankers were found on every branch exhibiting spruce decline symptoms in our survey, with one exception, and thus cankers play an important role in spruce decline. Interestingly, branches did not display any outward symptoms of cankers; they were only evident once the bark layer was removed (Fig. 1B). Cankers were brown with a distinct margin, restricted to the bark and vascular cambium, and with only occasional resinous streaking.

In order to identify the likely pathogen(s) causing cankers in the spruce decline system, the following criteria were considered: i) There was a wide distribution of the fungal genus throughout Michigan, since spruce decline was found throughout Michigan, ii) the frequency of isolation from cankers was consistently high in all regions, iii) there was evidence for pathogenicity, and iv) the symptoms of infection following greenhouse inoculations matched spruce decline symptoms in the field.

Using these criteria, Cytospora, which is reported to be a common and damaging canker-causing pathogen of spruce in the central and eastern United States (Sinclair and Lyon 2005), was detected in only $1.4 \%$ of the cankers sampled from trees exhibiting spruce decline.
Cytospora also was not widely distributed, as it was not recovered from all regions studied (Fig. 3). Similar to spruce decline, Cytospora kunze $i$ attacks older trees and involves cankers that kill branches, often starting from the bottom of the tree, but $C$. kunzei will usually disfigure the tree instead of kill it. Additionally, a tree infected with C. kunzei will exude copious amounts of resin that will form a white crust around the canker site. In contrast, we have not detected any similar outward symptoms on trees with spruce decline at the canker site. Thus, we assert that $C$. kunzei is unlikely to be the main pathogen causing spruce decline in Michigan. The other two known canker pathogens of conifers, Pestalotiopsis and Fusarium, were isolated at very low rates within the survey, suggesting that they are also not likely to be a major cause of branch death in declining spruce.

Of the five most commonly isolated genera in the survey, Diplodia, Alternaria, and Epicoccum had patchy distributions where the genera were rare or absent in northern and western regions of

Table 3. GLM analysis for inoculation experiment to determine differences in virulence across five Diaporthe haplotypes. The degrees of freedom in the denominator was 214 for all comparisons.

\begin{tabular}{lccc}
\hline Effect & $\begin{array}{c}\text { Degrees of } \\
\text { freedom }\end{array}$ & F-value & Probability $>$ F \\
\hline Diaporthe haplotype (DH) & 6 & 22.62 & $<0.0001$ \\
Spruce taxon (ST) & 2 & 4.73 & 0.0098 \\
DH by ST interaction & 12 & 1.73 & 0.0626 \\
\hline
\end{tabular}

Fig. 6. (Continued from previous page)

B

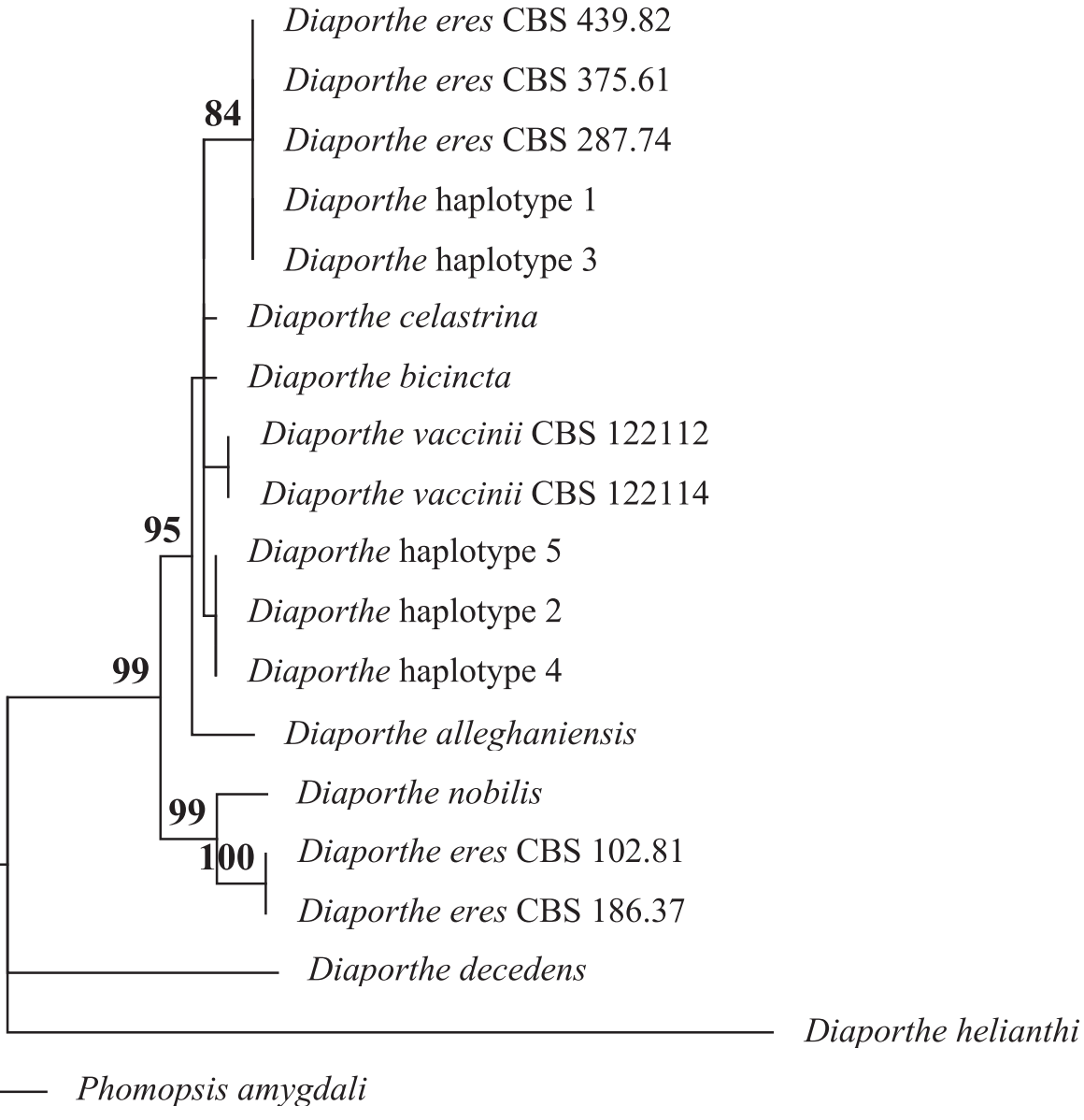

Diaporthella corylina 
Michigan's Lower Peninsula, thus violating our criterion that the spruce decline pathogen should be common in all regions where spruce decline is common. However, Diplodia (isolated from $14.75 \%$ of all sampled cankers) was detected in all regions, but less so in the west and north regions (Fig. 3). While sequencing is underway, we suspect many are $D$. pinea, the pathogen causing Diplodia tip blight of pines (Sinclair and Lyon 2005). Michigan is currently experiencing a severe Diplodia tip blight epidemic on pines, and it is likely these pines are serving as reservoirs for nearby stressed spruce (O'Donnell 2014; Sinclair and Lyon 2005). Our preliminary work also provides evidence that at least some of these Diplodia isolates can cause cankers on mature blue spruce (C. K. McTavish, unpublished data). Thus, Diplodia is associated with spruce decline in areas where Diplodia tip blight is a problem, but due to the patchiness of recovery, it cannot be a main pathogen contributing to spruce decline.

Paraconiothyrium (isolated from $33.5 \%$ of all sampled cankers) was one of the most common genera in this study, and was ubiquitous throughout Michigan (Fig. 3), which suggests it might be involved in the spruce decline epidemic. However, Paraconiothyrium was regularly isolated from both healthy spruce tissue as well as canker tissue (C. K. McTavish, unpublished data). It was also reported as an endophyte with the ability to elicit taxol production in the tree that acts as a fungicide (Soliman et al. 2013). The chemical properties of this taxon could conceivably limit other fungi from invading, making it a beneficial fungus for the tree. Taking all this into account, while this group fit the distribution and frequency criteria, there was a lack of pathogenicity evidence and no previously described symptoms to our knowledge for Paraconiothyrium to be a pathogen causing spruce decline.

Diaporthe was also frequently isolated from cankers on symptomatic branches (isolated from $32.32 \%$ of all cankers) (Fig. 3). Found in every region, it was also the only fungus isolated from every site studied. The Diaporthe genus contains species that are plant pathogens, saprobes, and endophytes, many of which have wide host

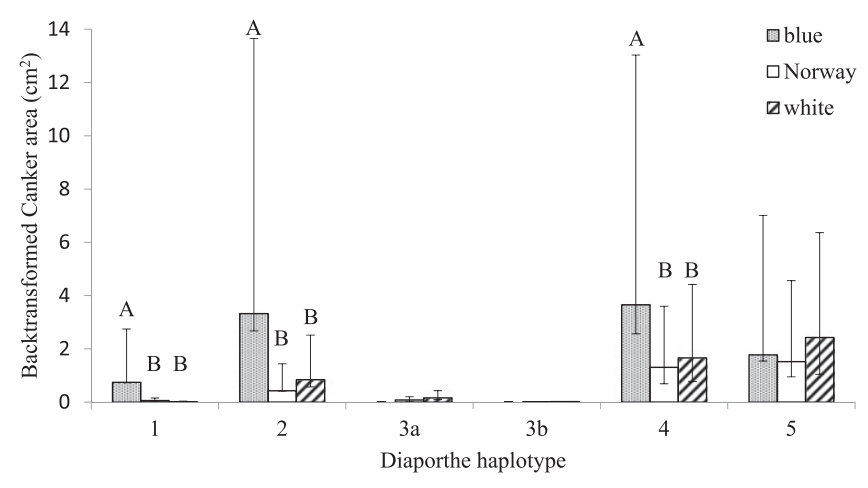

Fig. 7. Back-transformed mean canker area $\left(\mathrm{cm}^{2}\right)$ caused by Diaporthe haplotypes on blue (Picea pungens), Norway (P. abies), and white spruce (P. glauca). Error bars represent back-transformed $95 \%$ confidence interval. Capital letters above the bars indicate differences among tree species susceptibility to a particular Diaporthe haplotype. Canker sizes did not differ among the three spruce taxa when inoculated with haplotypes $3 \mathrm{a}, 3 \mathrm{~b}$, and 5 . Negative controls did not yield cankers (data not presented).

Table 4. Average canker sizes for Diaporthe isolates. Sizes represent the average canker size across the three spruce species inoculated; blue ( $P$. pungens), Norway ( $P$. abies), and white spruce ( $P$. glauca). Values followed by the same letter do not differ statistically.

\begin{tabular}{lcc}
\hline $\begin{array}{l}\text { Diaporthe haplotype } \\
\text { (isolate \#) }\end{array}$ & $\begin{array}{c}\text { Average canker } \\
\text { size }\end{array}$ & $\begin{array}{c}\text { Tukey-Kramer } \\
\text { comparisons }\end{array}$ \\
\hline $4(53)$ & 2.058 & $\mathrm{a}$ \\
$5(82)$ & 1.885 & $\mathrm{a} \mathrm{b}$ \\
$2(5)$ & 1.249 & $\mathrm{~b}$ \\
$1(90)$ & 0.231 & $\mathrm{c}$ \\
$3(15)$ & 0.080 & $\mathrm{c}$ \\
$3(68)$ & 0.011 & $\mathrm{c}$ \\
\hline
\end{tabular}

ranges (Gomes et al. 2013; Santos and Phillips 2009; Udayanga et al. 2011). Similar to D. juniperova, which causes juniper blight, $D$. occulta was reported to attack $P$. pungens and $P$. engelmanni when trees were stressed due to improper cultivation conditions (White 1929). Sieber (1989) studied twigs on healthy and diseased trees, and found that D. occulta was isolated frequently and, at one site, was statistically more linked with diseased Norway spruce than healthy ones, while Alternaria alternata, Epicoccum nigrum, and Cytospora were only rarely isolated. Furthermore, D. occulta has already been reported as causing disease on younger spruce trees: it was reported to cause tip curling and death along with stem cankers on spruce nursery and tree farm stocks in Wisconsin (Sanderson and Worf 1986) and later causing cankers on spruce in nursery and tree farm settings in Michigan (Igoe et al. 1995). While other fungi may exacerbate the expression of spruce decline symptoms, and stress due to abiotic and biotic factors may play important roles in tree decline progression, Diaporthe was the only genus encountered in this study that met all four criteria of frequency, distribution, symptomology, and evidence of pathogenicity, and therefore is the most important canker causing pathogen responsible for spruce decline symptoms.

Only five Diaporthe haplotypes were detected with ITS using 43 samples collected across the northern Lower Peninsula of Michigan, confirming preliminary work (D. W. Fulbright and S. Stadt, unpublished data). The $\beta$-tubulin gene sequences only differentiated haplotypes 2, 4, and 5 further from haplotypes 1 and 3 by 5 additional bp. Phylogenetic results did not classify the haplotypes to species level, but there were notable findings. The low virulence haplotypes, 1 and 3, fell into well-supported D. eres clade(s) (Figs. 4, 5, and 6), which has a large host range including Acer, Castanea, Corylus, Juglans, Picea, Prunus, and Viburnum, and has been reported to be pathogenic or weakly pathogenic on many of these hosts (Gomes et al. 2013; Thomidis and Michailides 2009; Udayanga et al. 2014). Phomopsis occulta, the pathogen identified for spruce canker and tip

Table 5. GLM analysis for inoculation experiment to determine differences in spruce taxa susceptibility using three Diaporthe isolates

\begin{tabular}{lcrr}
\hline Effect & Numerator DF & F value & Pr $>$ F \\
\hline Spruce taxon & 5 & 55.32 & $<0.0001$ \\
Diaporthe haplotype & 3 & 395.71 & $<0.0001$ \\
Main stem diameter & 101 & 1.15 & 0.1556 \\
Taxon $\times$ haplotype & 15 & 23.86 & $<0.0001$ \\
\hline
\end{tabular}

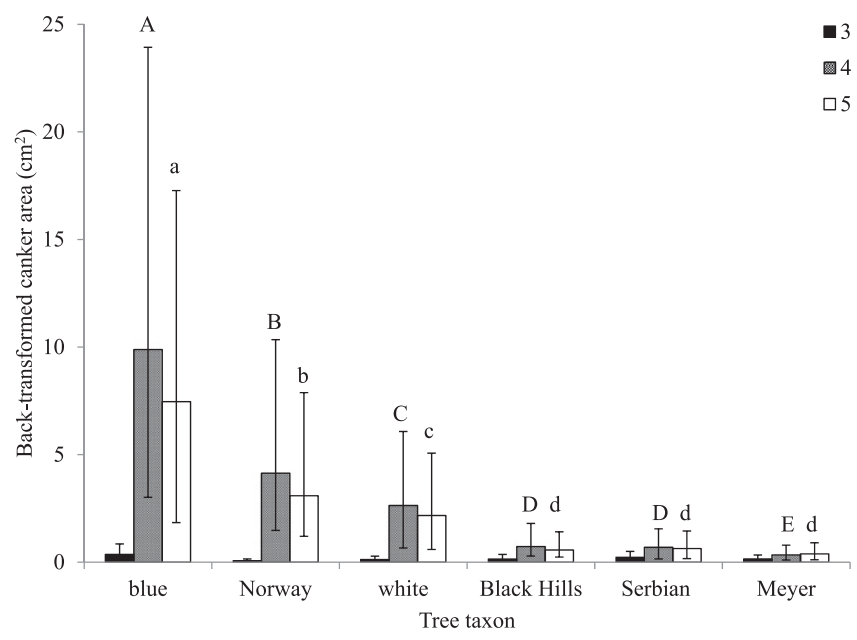

Fig. 8. Back-transformed mean Diaporthe canker area $\left(\mathrm{cm}^{2}\right)$ of isolates on 3-year-old blue ( $P$. pungens), Norway ( $P$. abies), white ( $P$. glauca), Black Hills ( $P$. glauca var. densata), Serbian (P. omorika), and Meyer ( $P$. meyeri) nursery spruce trees. Error bars represent the $95 \%$ confidence interval, and upper and lowercase letters represent post hoc analyses of haplotype 4 and 5 differences, respectively. Canker sizes did not differ among the six spruce taxa when inoculated with haplotype 3. Negative controls did not yield cankers (data not presented). 
blight, has been proposed to be renamed D. eres (Igoe et al. 1995; Rossman et al. 2014; Sanderson and Worf 1986). In contrast, haplotypes 2,4 , and 5 were grouped into unresolved portions of the cladograms, which included D. bicincta (host: dead Juglans spp.) and D. celastrina (host: Celastrus scandens). These findings hint at the possibility that more than one Diaporthe species is involved in spruce decline. The genetic variability of haplotypes further supported the theory of multiple Diaporthe species involved in spruce decline. Haplotypes 4, 5, and 2 were only different by 1 or 2 bp changes in ITS and identical in TUB, were more virulent than the less similar (up to 9 bp changes from haplotypes 4,5 , and 2 using ITS) but resolved haplotypes 1 and 3 . Results were similar with TUB, with 5 bp differences between the groupings of haplotypes 2, 4, and 5 and haplotypes 1 and 3. Taxonomical work is not complete: further sequencing with additional genes is already underway to identify the species names of Diaporthe causing spruce decline.

The five Diaporthe haplotypes differed in their virulence on Colorado blue, Norway, and white spruce (Fig. 7). The genetically similar haplotypes 2, 4, and 5 were virulent on Colorado blue, Norway, and white spruce (Fig. 7). Haplotype 1, which differed from the virulent group by 7 or 8 bp changes, was only slightly virulent on Colorado blue spruce and was essentially avirulent on Norway and white spruce. The most distinct haplotype 3 was essentially avirulent on spruce. Additionally, Diaporthe haplotypes inoculated onto spruce trees could be isolated readily from the resulting cankers, thus completing Koch's postulates. The grouping of haplotypes 2, 4, and 5 were therefore differentiated biologically (virulence) and genetically (increased bp changes) from haplotypes 1 and 3 .

Interestingly, spruce taxa differed in their resistance to the virulent haplotypes 4 and 5. Colorado blue spruce was the most susceptible host while Norway and white spruce were moderately susceptible (Fig. 8). Black Hills, Serbian, and Meyer spruce were the least susceptible to these Diaporthe haplotypes. It was surprising that Black Hills spruce ( $P$. glauca var. densata) differed from the closely related white spruce $(P$. glauca). This suggests that resistance to spruce decline could be relatively easy to evolve. Our data suggests that more resistant spruce could be considered as substitutes for the relatively susceptible Colorado blue and Norway spruce in future landscape plantings. However, these potential replacements may have other drawbacks that reduce their appeal as plantings in the landscape. For example, Serbian spruce is more susceptible to the white pine weevil, and Meyer spruce grows more slowly than Colorado blue spruce (Bert Cregg, personal communication).

When comparing inoculation experiments from 2013 and 2014, there were differences between canker sizes, although the patterns remained the same. This could be due to improvement on inoculation technique or the impact of tree stress on canker size, as the second experiment was performed in a different greenhouse without swamp coolers. Additionally, while the sample size of the 2014 experiment was larger (60 treatment replications versus 15), the confidence intervals were not improved upon, particularly the larger upper confidence

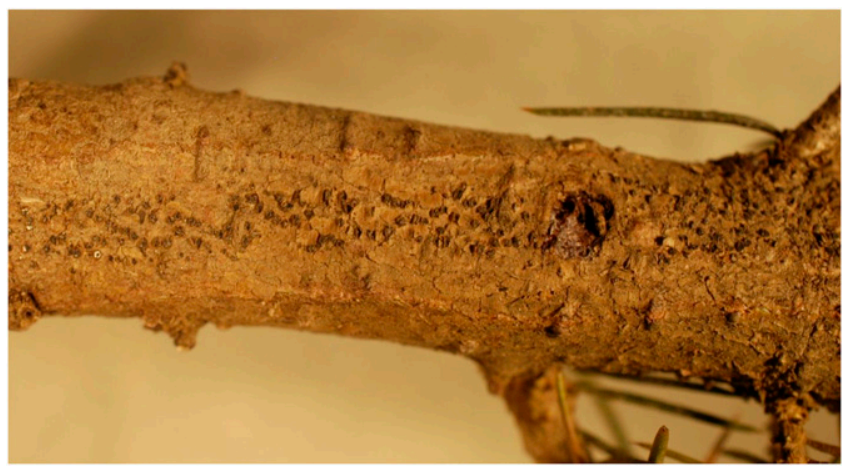

Fig. 9. Norway spruce inoculated with Diaporthe haplotype 5 exhibiting dark spore structures and canker indentation. Note the inoculation hole on the right side of the image. intervals. Sometimes there would be more susceptible trees within a spruce taxon, particularly in Colorado blue spruce. This demonstrates that trees are not clones of each other, and thus one tree will not have exactly the same reaction as another in the same taxon, even with the same general stressors. Unfortunately, these inoculation experiments were not designed to explicitly evaluate tree stress on spruce decline symptoms; therefore, the role of stress will need to be determined in more detail with future experiments.

Based on past studies of Diaporthe and spruce trees, the etiology suggests that Diaporthe is in nurseries and tree farms (Igoe et al. 1995; Sanderson and Worf 1986). Indeed, growers have reported problems associated with Diaporthe in their nurseries and tree farms with similar spruce decline symptoms of needle loss and death of lower branches, but full spruce decline symptoms as seen on mature spruce do not usually develop due to aggressive disease management regimes. Currently, it is unclear whether Diaporthe causing symptoms in nurseries and tree farms is the same species recovered in this study from landscape spruce. Based on our haplotype findings, there could be more than one Diaporthe species causing disease.

It is also unclear how spruce decline incidence became so widespread in a relatively short amount of time. Diaporthe may normally be a latent endophyte in mature trees, or a weak pathogen (Diogo et al. 2010; Gomes et al. 2013; Udayanga et al. 2011) until biotic or abiotic stressors trigger a more virulent phase that leads to spruce decline. Results reported here suggest that Diaporthe has a large role in the spruce decline epidemic, but it may not be the only factor responsible for spruce decline. Tree declines are complex and often include complicated etiologies that include environmental influences that play a key role in host decline (Manion 1991). Spruce trees are widely planted outside of their native range, perhaps predisposing these trees to stress. It could be site selection factors, changing seasonal rainfall patterns in Michigan (Andresen et al. 2012), or climate change generally that may be acting to stress spruce over wide areas. Sanderson and Worf (1986) reported that higher temperatures and humidity induce more symptom development in nursery settings, and those conditions may predispose mature landscape trees to develop spruce decline symptoms when Diaporthe is present. Alternatively, trees may be weakened due to shallow roots and nutrient deficiencies that may further exacerbate spruce decline. Needle cast and insect diseases, which individually cannot cause all the spruce decline symptoms, are common throughout Michigan, and another fungus, Stigmina lautii, was reported as associated with needle cast symptoms at the same time spruce decline symptoms were first being identified (Fulbright 2008, 2010; Fulbright et al. 2011). What remains to be determined is which stressor or combination of stressors is responsible for the sudden increase in spruce decline. Further work

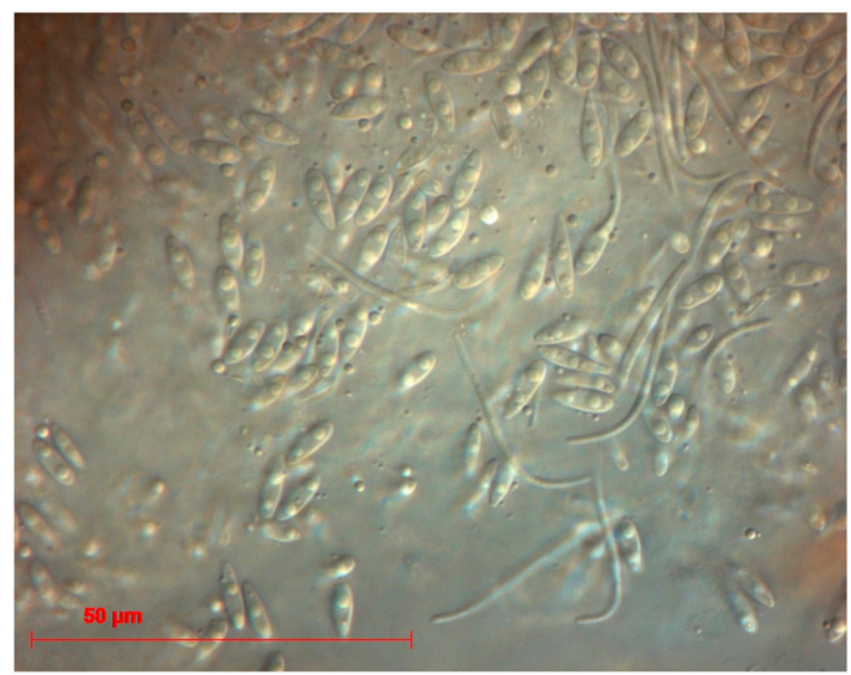

Fig. 10. Spheroid-shaped alpha conidia and long, thin, and curved beta conidia isolated from Diaporthe spore structures. 
also needs to explore spruce taxa, including Colorado blue spruce, for useful sources of resistance.

Though studies presented in this work were limited to Michigan, surrounding states as well as more distant states like New York have reported similar symptoms, particularly with Colorado blue spruce. Genetic work at a larger scale could shed light on where Diaporthe originated, if it is not an endophyte, or became latent after infection in a nursery. It is currently unknown how Diaporthe is spreading both within the tree and among trees, particularly because a sexual stage has not been observed. Due to these unsolved questions, methods to control spruce decline, other than reducing stress and using good site selection, remain uncertain. In the meantime, dead branch removal on trees should help to reduce inoculum. Avoiding damage during wet conditions will also assist the control of spruce decline. Using good arboricultural techniques to maintain tree vitality as well as reducing competition from other plants and pathogens will minimize tree stress, lowering susceptibility to disease.

\section{Acknowledgments}

Many thanks go to Sara Stadt, Matthew Chansler, Daphna Gadoth-Goodman, Joel Peven, Jill O'Donnell, Bert Cregg, and countless others for their ideas, contributions, and support in this research.

\section{Literature Cited}

Andresen, J., Hilberg, S., and Kunkel, K. 2012: Historical Climate and Climate Trends in the Midwestern USA. In: U.S. National Climate Assessment Midwest Technical Input Report. J. Winkler, J. Andresen, J. Hatfield, D. Bidwell, and D. Brown, coordinators. http://glisa.umich.edu/media/files/NCA/MTIT_ Historical.pdf

Bandelt, H., Forster, P., and Röhl, A. 1999. Median-joining networks for inferring intraspecific phylogenies. Mol. Biol. Evol. 16:37-48.

Catal, M., Adams, G. C., and Fulbright, D. W. 2010. Evaluation of resistance to Rhabdocline needlecast in Douglas fir variety Shuswap, with quantitative polymerase chain reaction. Phytopathology 100:337-344.

Crous, P. W., and Groenewald, J. Z. 2005. Hosts, species and genotypes: Opinions versus data. Australas. Plant Pathol. 34:463-470.

Diogo, E. L. F., Santos, J. M., and Phillips, A. J. L. 2010. Phylogeny, morphology and pathogenicity of Diaporthe and Phomopsis species on almond in Portugal. Fungal Divers. 44:107-115.

Felsenstein, J. 1985. Confidence limits on phylogenies: An approach using the bootstrap. Evolution 39:783-791.

Fulbright, D. W. 2008. Stigmina found associated with needle cast on blue spruce in Michigan. Retrieved from http://msue.anr.msu.edu/news/stigmina_found_ associated_with_needle_cast_on_blue_spruce_in_michigan

Fulbright, D. W. 2010. Stigmina on spruce in Michigan. In: Proceedings of the 9th International Christmas Tree Research and Extension Conference. J. Hart, C. Landgren, and G. Chastagner, eds. Corvallis, Oregon and Puyallup, Washington.

Fulbright, D. W., Catal, M., Stadt, S., and O'Donnell, J. 2011. Spruce tree problem shows symptoms of both needlecast and branch death. Retrieved from http:// msue.anr.msu.edu/news/spruce_tree_problem_shows_symptoms_of_both_needlecast_ and_branch_death

Glass, N. L., and Donaldson, G. C. 1995. Development of primer sets designed for use with the PCR to amplify conserved genes from filamentous ascomycetes. Appl. Environ. Microbiol. 61:1323-1330.

Gomes, R. R., Glienke, C., Videira, S. I. R., Lombard, L., Groenewald, J. Z., and Crous, P. W. 2013. Diaporthe: a genus of endophytic, saprobic and plant pathogenic fungi. Persoonia 31:1-41.

Hall, T. A. 1999. BioEdit: a user-friendly biological sequence alignment editor and analysis program for Windows 95/98/NT. Nucl. Acids. Symp. Ser. 41: 95-98.

Hansen, E. M., and Lewis, K. J. 1997. Compendium of Conifer Diseases. The American Phytopathological Society, St. Paul, Minnesota.

Hodges, C. S. 2002. First Report of Stigmina lautii in the United States. Plant Dis. 79:202-205.

Igoe, M. J., Peterson, N., and Roberts, D. 1995. A Phomopsis canker associated with branch dieback of Colorado blue spruce in Michigan. Plant Dis. 79: 202-205.

Kimura, M. 1980. A simple method for estimating evolutionary rate of base substitutions through comparative studies of nucleotide sequences. J. Mol. Evol. 16:111-120.

Manion, P. D. 1991. Tree Disease Concepts, 2nd Ed. Prentice-Hall, Englewood Cliffs, NJ.
Michigan Department of Agriculture and USDA NASS. 2005. Michigan Rotational Survey, Nursery and Christmas Trees 2004-2005.

Nei, M., and Kumar, S. 2000. Molecular Evolution and Phylogenetics. Oxford University Press, New York.

O’Donnell, J. 2014. Diplodia tip blight management in trees. Michigan State University Extension. Retrieved from http://msue.anr.msu.edu/news/diplodia tip_blight_management_in_trees

Rambaut, A. 2012. FigTree. Molecular evolution, phylogenetics, and epidemiology. The University of Edinburgh. http://tree.bio.ed.ac.uk/software/ figtree/

Rehner, S. A., and Uecker, F. A. 1994. Nuclear ribosomal internal transcribed spacer phylogeny and host diversity in the coelomycete Phomopsis. Can. J. Bot. 72:1666-1674.

Ronquist, F., and Huelsenbeck, J. P. 2003. MRBAYES 3: Bayesian phylogenetic inference under mixed models. Bioinformatics 19:1572-1574.

Rossman, A., Udayanga, D., Castlebury, L. A., and Hyde, K. D. 2014. Proposal to conserve the name Diaporthe eres against twenty-one competing names (Ascomycota: Diaporthales: Diaporthaceae). Taxon 63:934-935.

Rossman, A. Y., Farr, D. F., Castlebury, L. A., Shoemaker, R., and Mengistu, A. 2002. Setomelanomma holmii (Pleosporales, Phaeosphaeriaceae) on living spruce twigs in Europe and North America. Can. J. Bot. 80:1209-1215.

Saitou, M., and Nei, M. 1987. The neighbor-joining method: A new method for reconstructing phylogenetic trees. Mol. Biol. Evol. 4:406-425.

Sanderson, P. G., and Worf, G. L. 1986. Phomopsis shoot blight of Colorado Blue Spruce. J. Environ. Hortic. 4:134-138.

Santos, J., and Phillips, A. 2009. Resolving the complex of Diaporthe (Phomopsis) species occurring on Foeniculum vulgare in Portugal. Fungal Divers. 34: 111-125.

SAS Institute. 2013. SAS Programming Documentation, version 9.4. SAS Institute Cary, NC.

Sieber, T. N. 1989. Endophytic fungi in twigs of healthy and diseased Norway spruce and white fir. Mycol. Res. 92:322-326.

Sinclair, W. A., and Lyon, H. H. 2005. Diseases of Trees and Shrubs, 2nd Ed. Comstock Publishing Associates, Ithaca, NY.

Soliman, S. S. M., Trobacher, C. P., Tsao, R., Greenwood, J. S., and Raizada, M. N. 2013. A fungal endophyte induces transcription of genes encoding a redundant fungicide pathway in its host plant. BMC Plant Biol. 13:93.

Swofford, D. L. 2002. PAUP*. Phylogenetic Analysis Using Parsimony (*and Other Methods). Version 4.0a159. Sinauer Associates, Sunderland, MA.

Tamura, K. 1992. Estimation of the number of nucleotide substitutions when there are strong transition-transversion and $\mathrm{G}+\mathrm{C}$-content biases. Mol. Biol. Evol. 9: 678-687.

Tamura, K., Stecher, G., Peterson, D., Filpski, A., and Kumar, S. 2013. MEGA6: Molecular Evolutionary Genetics Analysis version 6.0. Mol. Biol. Evol. 30: 2725-2729.

Thomidis, T., and Michailides, T. J. 2009. Studies on Diaporthe eres as a new pathogen of peach trees in Greece. Plant Dis. 93:1293-1297.

Udayanga, D., Castlebury, L. A., Rossman, A. Y., Chukeatirote, E., and Hyde, K. D. 2014. Insights into the genus Diaporthe: phylogenetic species delimitation in the D. eres species complex. Fungal Divers. 67:203-229.

Udayanga, D., Liu, X., McKenzie, E. H. C., Chukeatirote, E., Bahkali, A. H., and Hyde, K. D. 2011. The genus Phomopsis: biology, applications, species concepts and names of common phytopathogens. Fungal Divers. 50:189-225.

Uddin, W., Stevenson, K., and Pardo-Schultheiss, R. 1997. Pathogenicity of species of Phomopsis causing a shoot blight on peach in Georgia and evaluation of possible infection courts. Plant Dis. 81:983-989.

Uecker, F. A. 1988. A world list of Phomopsis names with notes on nomenclature, morphology and biology. Mycologia Memoir vol. 13. Lubrecht \& Cramer Ltd., Port Jervis, NY.

USDA NASS. 2012. 2012 Census of Agriculture. Table 35. Cut Christmas Trees: 2012 and 2007. USDA National Agricultural Statistics Service. Available online: https://www.agcensus.usda.gov/Publications/2012/Full_Report/Volume_1,_Chapter_ 2_US_State_Level/st99_2_035_035.pdf

USDA NASS. 2014. 2013-2014 Michigan Christmas Trees. USDA National Agricultural Statistics Service, Great Lakes Region. Available online: https:// www.nass.usda.gov/Statistics_by_State/Michigan/Publications/archive/tree13. pdf

Wade, C. A. 2010. Ecological change in the urban forest of six Midwest, USA cities over twenty-five years. Michigan State University Ph.D. dissertation.

Walla, J., and Kinzer, K. 2006. Stigmina lautii discovered on spruce in North Dakota. Tree Talk-NDSU Ext. Serv. 2:13-18.

White, R. P. 1929. Juniper blight. Pages 270-272 in: Fiftieth Annual Report New Jersey Agriculture Experiment Station for the year ending June 30, 1929.

White, T. J., Bruns, T., Lee, S., and Taylor, J. W. 1990. Amplification and direct sequencing of fungal ribosomal RNA genes for phylogenetics. Pages 315-322 in: PCR Protocols: A Guide to Methods and Applications. M. A. Innis, D. H Gelfand, J. J. Sninsky, and T. J. White, eds. Academic Press, Inc., New York. 